\title{
SPATIALLY AVERAGED TENSILE MECHANICS FOR CRACKED CONCRETE AND REINFORCEMENT UNDER HIGHLY INELASTIC RANGE
}

\author{
Hamed SALEM ${ }^{1,2}$ and Koichi MAEKAWA ${ }^{3}$ \\ ${ }^{1}$ Member of JSCE, Ph.D., Post Doctoral Fellow, Dept. of Civil Eng., The University of Tokyo (Hongo 7-3-1, \\ Bunkyo-ku, Tokyo 113, Japan) \\ ${ }^{2}$ Assistant Professor, Structural Engineering Department, Cairo University (Giza, Egypt) \\ ${ }^{3}$ Member of JSCE, Dr. of Eng., Professor, Dept. of Civil Eng., The University of Tokyo (Hongo 7-3-1, Bunkyo- \\ ku, Tokyo 113, Japan)
}

\begin{abstract}
The aim of this study is to get the spatial average stress- average strain relationships of both reinforcing bars and cracked concrete in RC members based on the local bond characteristics between concrete and reinforcing bars. The computation is capable of predicting the crack spacing and the ultimate average strain of reinforcing bars when total rupture takes place. The systematic verification through experimental works is conducted for clarifying the versatility of the proposed model.
\end{abstract}

Key Words: bond-slip-strain, tension stiffening, crack spacing

\section{INTRODUCTION}

The tension stiffening effect represents the capacity of concrete to carry the internal tensile force developing between adjacent cracks. At distinct cracked sections, the local tensile force is carried by both steel reinforcing bars and concrete residual softened tension. The force developing in reinforcement is partly transferred to concrete between adjacent cracks through bond stress transfer between reinforcing bars and concrete, while the residual tensile stresses at crack sections are applied directly to the fracturing planes. The tension stiffening effect is usually treated by assuming a relationship between the average concrete tensile stress and the average concrete tensile strain over a long-gauge length in the direction normal to cracks (Shima et al. ${ }^{4}$ ).

At the same time, the stress-strain relationship of reinforcement has to be on average basis. As the stress in reinforcement embedded in concrete varies along its axis, the average stress-average strain relationship of reinforcement is significantly different from pointwise behavior of bare bar after yielding (Shima et al. ${ }^{4}$ ). The bar starts to yield at concrete cracks prior to the remaining parts. Therefore, the spatial average yield stress generally becomes lower than the yield stress of bare bar as clearly pointed out by Okamura and Maekawa ${ }^{5)}$.
After yielding, some parts of reinforcement close to cracks come into the strain hardening zone, whereas the remaining parts are still in the elastic zone. Therefore, the average response has stiffness mixed from the elastic and the hardening one. Usually, a bilinear model is assumed for the average response of steel bars.

Shima et al. ${ }^{4)}$ assumed that the reinforcing bar stress has a full cosine profile, and based on this distribution they got the average stress-average strain relationship of reinforcing bars. Their choice of a cosine stress distribution was based on the fact that cosine function is a symmetric one and its derivative is zero at both the cracked section and the center of the segment. This agrees well with the fact that the bond stresses at the cracks and at the midway between two successive cracks are zero.

Belarbi and $\mathrm{Hsu}^{6)}$ assumed another stress profile, which is the summation of Shima's cosine function and two other sinusoidal functions. The purpose of this modification was to simulate the fact that after yielding of reinforcing bars the bond stress between reinforcing bars and concrete deteriorates and the reinforcing bar stress in the vicinity of the cracks becomes uniform.

Assumptions of both Shima and Belarbi are acceptable for middle and highly reinforced concrete, where the spacing of cracks is relatively 
small. However, for lightly reinforced concrete, the crack spacing is larger and tends to be localized like plain concrete. In this case, both Shima and Belarbi's stress distributions are no longer valid and the local steel stress has to be computed from micro-bond characteristics.

The importance of considering tension softening at cracked sections arises in lightly reinforced concrete, as its contribution becomes higher compared to the contribution of bond stress transfer. In this study, both microscopic bond stress transfer and tension fracturing of plain concrete are coupled. The local stresses and strains of steel and concrete are computed, and hence the macroscopic behavior is evaluated.

In Shima and Belarbi's modeling, bond deterioration is indirectly taken into account and the absolute value of crack spacing is not necessarily incorporated, by assuming similarity of stress profile between cracks. But, in the past decade, some accumulation of knowledge on bond deterioration close to crack planes (Qureshi and Maekawa ${ }^{8)}$ ), and the fracturing process at a crack section have been made. The authors judged that it is a right time to re-construct the average based tension model of cracked concrete and embedded reinforcement, theoretically derived from microscopic mechanics with direct manner. For computing critical ductility, when steel ruptures inside concrete, the microscopic approach is indispensable since the rupture criterion is set just on the local behavior of steel. Furthermore, RC ductility with less reinforcement ratio is of great importance for seismic performance of existing large-scale structures. Low reinforcement cases in which the simplified stress profile cannot apply have been of interest to engineers involved in seismic analysis. This is another background, which the authors try to get more versatile modeling in smeared tension of reinforced concrete.

The present tension stiffening model proposed by Shima et al ${ }^{4)}$ is an empirical one and does not take into consideration the effect of amount of reinforcement. As a matter of fact, the experimentally obtained tension stiffness of cracked concrete is hardly affected by the reinforcement ratio (Okamura and Maekawa ${ }^{5)}$ ). However, the amount of reinforcement has a considerable effect on the tension stiffening of lightly reinforced members. In the present study, the tension stiffening is also analytically computed and the effect of amount of reinforcement is quantitatively taken into account.

The aim of this study is to get a versatile smeared tension model for reinforcing bars and

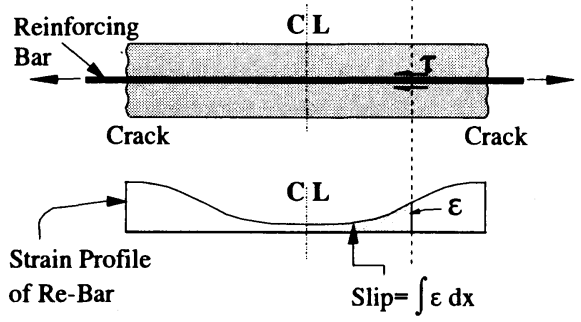

Fig. 1 Definition of slip in bond-slip-strain model (Shima et al. ${ }^{4)}$ )

concrete in both heavily and lightly reinforced concrete. At the same time, the average crack spacing and the average ultimate stress are computed.

\section{SPATIAL AVERAGED CONSTITUTIVE LAWS IN TENSION}

\section{(1) Bond-slip-strain model}

Shima et al. ${ }^{4)}$ proposed an universal bond stressaxial slip-steel strain model for RC. The model offers unique relationship that expresses the bond characteristics derived from both pullout and axial tension tests. The authors adopt this model for the local stress interaction between concrete and reinforcement as,

$$
\tau(\varepsilon, s)=\tau_{0}(s) g(\varepsilon)
$$

where, $\tau(\varepsilon, s)$ is local bond stress and $\tau_{0}(s)$ is intrinsic bond stress when strain is zero denoted by,

$$
\begin{gathered}
\tau_{0}(s)=f_{c}^{\prime} k[\ln (1+5 s)]^{c} \\
g(\varepsilon)=\frac{1}{1+10^{5} \varepsilon}
\end{gathered}
$$

where, $f_{\mathrm{c}}^{\prime}$ is compressive strength of concrete, $\mathrm{k}$ is constant $=0.73, \mathrm{c}$ is constant $=3, \mathrm{~s}$ is non dimensional slip $=1000 \mathrm{~S} / \mathrm{d}, \mathrm{S}$ is slip and $\mathrm{d}$ and $\varepsilon$ are diameter and strain of bar.

Fig. 1 shows the parameters used in the model. The model is applicable for both the elastic range and the post-yield range (Shima et al. ${ }^{4)}$ ). Using this model the phenomenon of bond reduction in the post-yield range can be coherently explained. When the reinforcing bar, in the vicinity of crack, starts to yield, the strain suddenly increases to the strain hardening zone leading to a drastic drop in the strain function denoted by $g(\varepsilon)$ in Eq.(3) . However, the slip function can be unchanged since the slip 


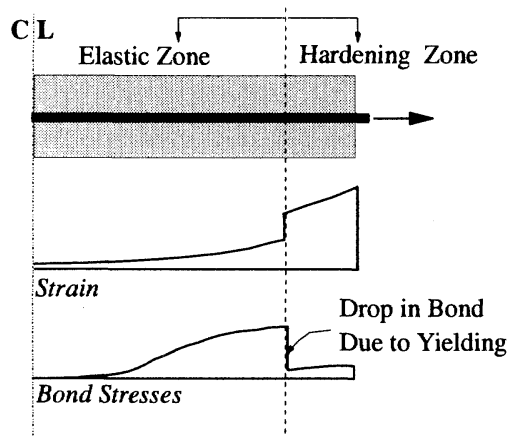

Fig. 2 Bond stresses in the post-yielding range

doesn't increase much. This is due to the fact that the integrated strain, that is equivalent to the slip, remains almost the same because the plastic region just after yield is so much limited. This drop of strain function causes a drop in the bond stress as shown in Fig. 2. It is also to be noted that the local bond in the post-yield range of steel is apparently influenced by the stress-strain characteristics and elasticity of bare bar. The drop in bond stress of reinforcement with short yield plateau is expected to be smaller than that of reinforcement with long yield plateau. This qualitative feature of bond mechanism can be systematically treated in use of local bond-slip-strain model. Then, the authors accepted this scheme for this investigation.

\section{(2) Bond Deterioration Model}

When the reinforcing bar is tensioned against concrete, the lugs of the reinforcing bar press against concrete causing conical diagonal compressive struts (Goto ${ }^{1)}$ ). Tensile stresses are generated in a direction perpendicular to these struts causing splitting conical cracks. In the vicinity of crack planes, these struts have no concrete to support because of the penetration of conical crack reaching to the crack planes. Therefore, concrete spalling easily occurs causing bond deterioration as shown in Fig. 3 (Qureshi and Maekawa ${ }^{8)}$ ). Shima's model can not be applied to that bond deterioration zone where the "near crack surface effect" is predominant (Okamura and Maekawa ${ }^{5}$ ).

In fact, the localization of plastic yielding is initiated from the bond deterioration zone. Thus, the modeling of bond close to cracks plays an important role for post-yield behavior of RC in tension. Qureshi and Maekawa ${ }^{8)}$ assumed in the RC joint model that 'he bond stress is linearly decreasing to zero at a distance $5 \mathrm{~d}$ (d is defined as diameter of a bar) from the crack surface, and that the bond stress drops suddenly to zero at a distance $2.5 \mathrm{~d}$ from the

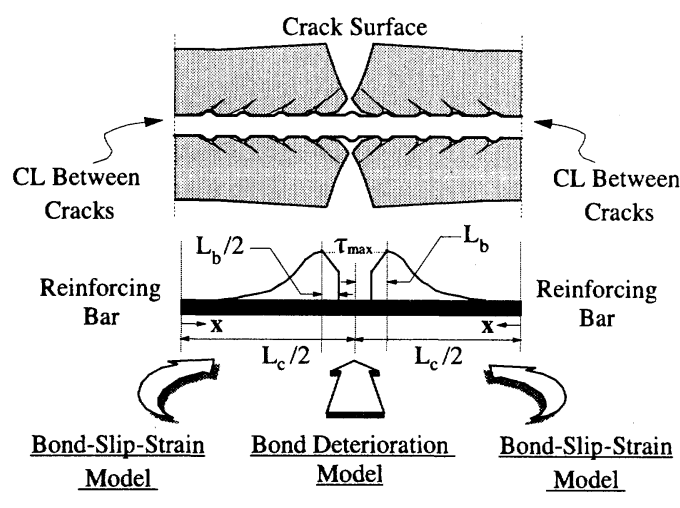

Fig. 3 Bond deterioration close to cracks (Qureshi and Maekawa ${ }^{8)}$ ).

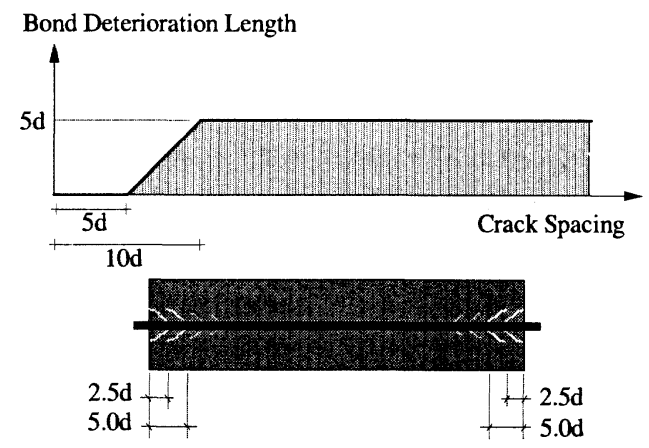

Fig. 4 Modification of bond deterioration model for small crack spacing

crack surface due to splitting and crushing of concrete around the bar beside the crack surface. Fig. 3 shows a schematic drawing of bond deterioration model, which describes,

$$
\begin{gathered}
\tau(x)=\tau_{\text {max }}-\frac{\tau_{\max }}{L_{b}}\left[x-\left(\frac{L_{c}}{2}-L_{b}\right)\right], \\
\frac{L_{c}}{2}-L_{b} \leq x \leq \frac{L_{c}}{2}-\frac{L_{b}}{2} \\
\tau(x)=0, \\
\frac{L_{c}}{2}-\frac{L_{b}}{2} \leq x \leq \frac{L_{c}}{2}
\end{gathered}
$$

However, it must be considered that when the crack spacing becomes smaller than $10 \mathrm{~d}$, the bond deterioration length cannot be logically equal to $5 \mathrm{~d}$ 
as the splitting conical cracks cannot physically intersect. Also, when the crack spacing becomes smaller than 5d, the concrete spalling cannot happen. Therefore, it was assumed that the bond deterioration length is equal to zero when the crack spacing is less than $5 \mathrm{~d}$, and it changes linearly from zero to $5 \mathrm{~d}$ when the crack spacing changes from $5 \mathrm{~d}$ to $10 \mathrm{~d}$ as shown in Fig. 4. Nevertheless, this case is very rare to occur and the case only when the reinforcement ratio is very high and the tensile strength is so small.

\section{(3) Tension Softening at Crack Surface}

When concrete is cracked, the stress carried by concrete at the crack surface does not drop to zero suddenly. The interlocking of the two faces of the crack causes a transfer of some residual stresses. This phenomenon is known as tension softening of plain concrete. Regarding reinforced concrete members with ordinary reinforcement ratios, this softening can be neglected compared to the force carried by bond stress transfer.

However, in case of small reinforcement ratio this softening may not be neglected. To study the effect of tension softening coupled with RC behaviors, combination of fracturing softening and bond tension stiffening is fruitful. Usually the tension softening is expressed as a relationship between the residual tensile stress and the crack width, which is the main parameter of tension softening. The surface crack width can be considered being compatible with the reinforcement slip at the crack. Thus, surface crack width is equal to the sum of the bar slip on both sides of the crack. In other words, the surface crack width is equal to twice the reinforcement slip, from one side, at the crack location. The average crack width used by Qureshi and Maekawa ${ }^{8)}$ is adopted here as,

$$
\mathrm{w}=\mathrm{C}\left(2 \mathrm{~S}_{\max }\right), \quad \mathrm{S}_{\max }=\left.\mathrm{S}\right|_{\mathrm{x}=\mathrm{L}_{\mathrm{c}} / 2}
$$

where $C$ is equal to $(1 / 1.3)$. The tension softening model adopted in the analysis (Uchida et al. ${ }^{7)}$ ) is defined as,

$$
\sigma_{\mathrm{br}}=f_{t}\left[1+0.5\left(\frac{f_{t}}{\mathrm{G}_{\mathrm{f}}}\right) \mathrm{w}\right]^{-3}
$$

where, $\sigma_{b r}$ is the bridging stress across crack, $f_{t}$ is the tensile strength, $w$ is the crack width and $G_{f}$ is the fracture energy ranging from 0.1 to $0.15 \mathrm{~N} / \mathrm{mm}$ for plain concrete ${ }^{7}$.

\section{LOCAL ANALYSIS AND AVERAGING}

In order to get the steel stress profile, other governing equations have to be simultaneously solved. By dividing the reinforcing bar between two adjacent cracks into infinitely small strips and satisfying the static equilibrium of all elements, we get the following continuum equilibrium equation as,

$$
\frac{\mathrm{d} \sigma}{\mathrm{dx}}=\frac{\pi \mathrm{d}}{\mathrm{A}_{\mathrm{s}}} \tau \Rightarrow \frac{\Delta \sigma}{\Delta \mathrm{x}}=\frac{\pi \mathrm{d}}{\mathrm{A}_{\mathrm{s}}} \bar{\tau} \text { (in computation) }
$$

where, $d \sigma / d x$ is axial stress gradient along the axis of reinforcing bar, As, $d$ are cross sectional area and diameter of reinforcing bar, and $\bar{\tau}$ is average bond stress.

The second equation is the bond-slip-strain model (Eq.(1), (2), and (3)), together with the bond model in the bond-deterioration zone (Eq. (4) and Eq.(5).). The third equation derives from the slip compatibility. The slip is computed by integrating the strain over the length of the reinforcing bar starting from the midway between adjacent cracks as shown in Fig. 1, i.e. the slip at the midway between cracks is zero. Thus, we have,

$$
S(x)=\int_{0}^{x} \varepsilon d x
$$

The fourth equation is the constitutive equation for the bare bar which represents the point-wise relationship between the reinforcing bar stress and strain at each bar section obtained from the uniaxial stress-strain relation of the bar used as,

$$
\begin{gathered}
\sigma=\mathrm{E}_{\mathrm{s}} \varepsilon \quad, 0<\varepsilon<\varepsilon_{\mathrm{y}} \\
\sigma=\mathrm{f}_{\mathrm{y}}, \varepsilon_{\mathrm{y}} \leq \varepsilon<\varepsilon_{\mathrm{sh}} \\
\sigma=\mathrm{f}_{\mathrm{y}}+\left\{1-\mathrm{e}^{\left(\varepsilon_{\mathrm{sh}}-\varepsilon\right) / \mathrm{k}}\right\}\left(1.01 \mathrm{f}_{\mathrm{u}}-\mathrm{f}_{\mathrm{y}}\right), \varepsilon>\varepsilon_{\mathrm{sh}} \\
\mathrm{k}=0.032\left(4000 / \mathrm{f}_{\mathrm{y}}\right)^{1 / 3}
\end{gathered}
$$

The overall scheme of computation is summarized in Fig. 5 and Fig. $6^{10), 11)}$. Firstly, the crack spacing is equal to the total length of the target control volume. Load is increased gradually and local stresses of both concrete and steel are computed. When the maximum local concrete stresses exceed the tensile strength of concrete, a new crack in the middle of specimen is introduced. Computations are carried out again with crack spacing equals to half the initial length. The new 
crack spacing in fact is the average crack spacing, since the real location of the crack is not necessarily in the middle of the specimen. The location of the crack depends on the distribution of the local tensile strength along the specimen length. Due to the nonuniformity of concrete, tensile strength along the specimen length is not uniform. For simplicity, the average crack spacing is assumed. Again, the load is increased gradually and the local concrete stresses are checked.

When the concrete stress exceeds the tensile strength, a new crack is introduced in the middle of one of the two halves of the specimen and an average crack spacing of one-third of the initial length is assumed as shown in Fig. 5. Cracking in only one half of the two halves is assumed, since in reality it is not possible to have two cracks simultaneously. This is experimentally verified by the fact that, the maximum crack spacing is twice the minimum crack spacing (Goto ${ }^{1)}$, and Rizkalla ${ }^{3)}$ ). After the formation of the second crack, it is possible to have the third crack in the other half of the specimen. Following the same concept, cracks are generated up to its stabilizing state. At this moment, there is no new crack generated. This state takes place either after yielding of reinforcement due to the drastic drop in the bond stresses or when the crack spacing becomes so small that the bond transfer length is incapable of transferring stresses sufficient to cause concrete cracking.

For computing stress profiles, finite discretization of the reinforcing bar between two successive cracks is performed as shown in Fig. 5 and Fig. 6. Starting from the midway between two adjacent cracks, a finite segment with length $\Delta \mathrm{x}$ is studied. The boundary conditions for this segment are set by equating both the slip and the bond stress at the middle section to zero, and assuming an arbitrary value to the strain at the middle. This arbitrary strain value represents the loading level. The four equations are simultaneously solved using an iterative procedure. Finishing the computation of this segment, the boundary conditions of the next division are defined and a similar computation procedure is followed. Hence, the strain and stress profiles of the steel reinforcement can be drawn. It results in the steel average stress and average strain as,

$$
\bar{\varepsilon}=\frac{2}{L_{c}} \int_{0}^{\frac{L_{c}}{2}} \varepsilon(x) d x \cong \frac{2}{L_{c}} \sum_{0}^{\frac{L_{c}}{2}} \varepsilon(x) \Delta x
$$

$$
\bar{\sigma}_{s}=\frac{2}{L_{c}} \int_{0}^{\frac{L_{c}}{2}} \sigma_{s}(x) d x \cong \frac{2}{L_{c}} \sum_{0}^{\frac{L_{c}}{2}} \sigma_{s}(x) \Delta x
$$

By computing the stress profile of reinforcement, the stress profile of concrete is obtained by subtracting reinforcement force profile from the reinforcing bar force at crack. Adding the bridging stress defined by Eq.(7), the average stress of concrete is mathematically defined as,

$$
\begin{aligned}
& \bar{\sigma}_{c}=\sigma_{b r}+\frac{2}{L_{c}} \int_{0}^{\frac{L_{c}}{2}} \sigma_{c}(x) d x \\
& \cong \sigma_{b r}+\frac{2}{L_{c}} \sum_{0}^{\frac{L_{c}}{2}} \sigma_{c}(x) \Delta x
\end{aligned}
$$

For a deeper understanding of the cracking behavior and the tension stiffening of concrete, Fig. 7 is provided. In this figure, the dashed curves represents the average stress-average strain relationship of concrete for different crack spacing considering no cracking at all and the solid curve represents the behavior when cracking is considered in the scheme proposed here. The initial considered specimen length is $3000 \mathrm{~mm}$, and the final crack spacing is $330 \mathrm{~mm}$. When a certain crack spacing is considered the typical curve is composed of two major parts, which are connected by a point representing the start of yielding of reinforcement. Before the yielding of reinforcement, the average stress of concrete is ascending, whereas after yielding it is descending. This is due to the fact that the bond stress suddenly decreases after yielding, resulting in a decrease in the load carried by concrete. Once this point is reached, it is strongly probable that no more cracks are generated. This is due to decrease in force transferred to concrete. In the shown sample in Fig. 7, the yielding starts when average crack spacing becomes $330 \mathrm{~mm}$, then no more cracks are computationally generated. Hence, the final crack spacing is designated as $330 \mathrm{~mm}$.

However, it was found in the analysis that when the cracking load of concrete is close to the yielding load of the reinforcement, mainly in case of low reinforcement ratio, cracking can occur after yielding, too. That's due to the fact that when the cracking load is close to the yielding load, the crack spacing is relatively larger. Therefore, the plasticity zone close to cracks is relatively small compared to the crack spacing. Hence, even though the average concrete stress is reduced after yielding, on the local level far from the crack surface, the local concrete stress is still increasing leading to new cracks. 

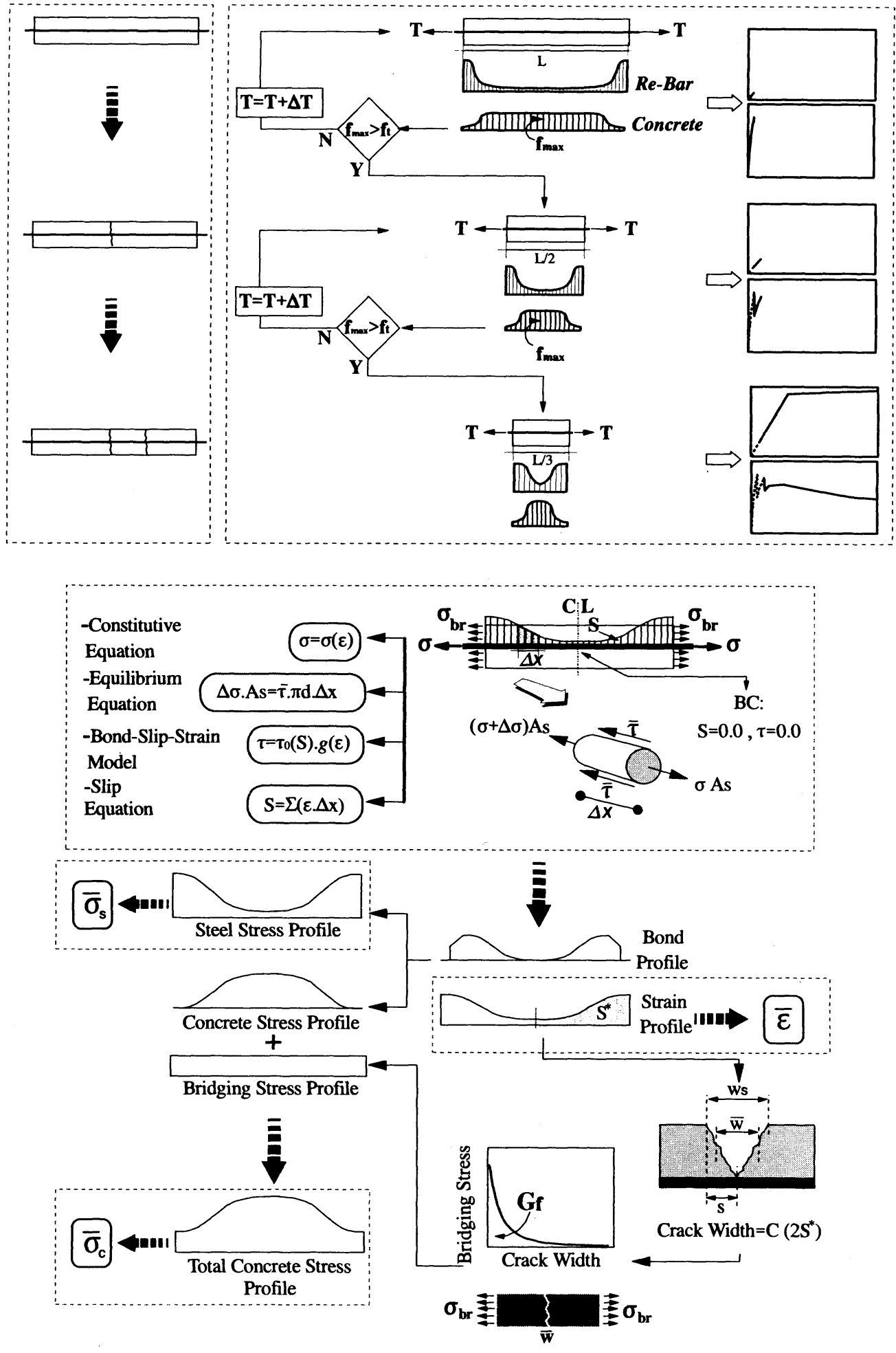

Fig. 5 Scheme of solving bond governing equations with finite discretization 

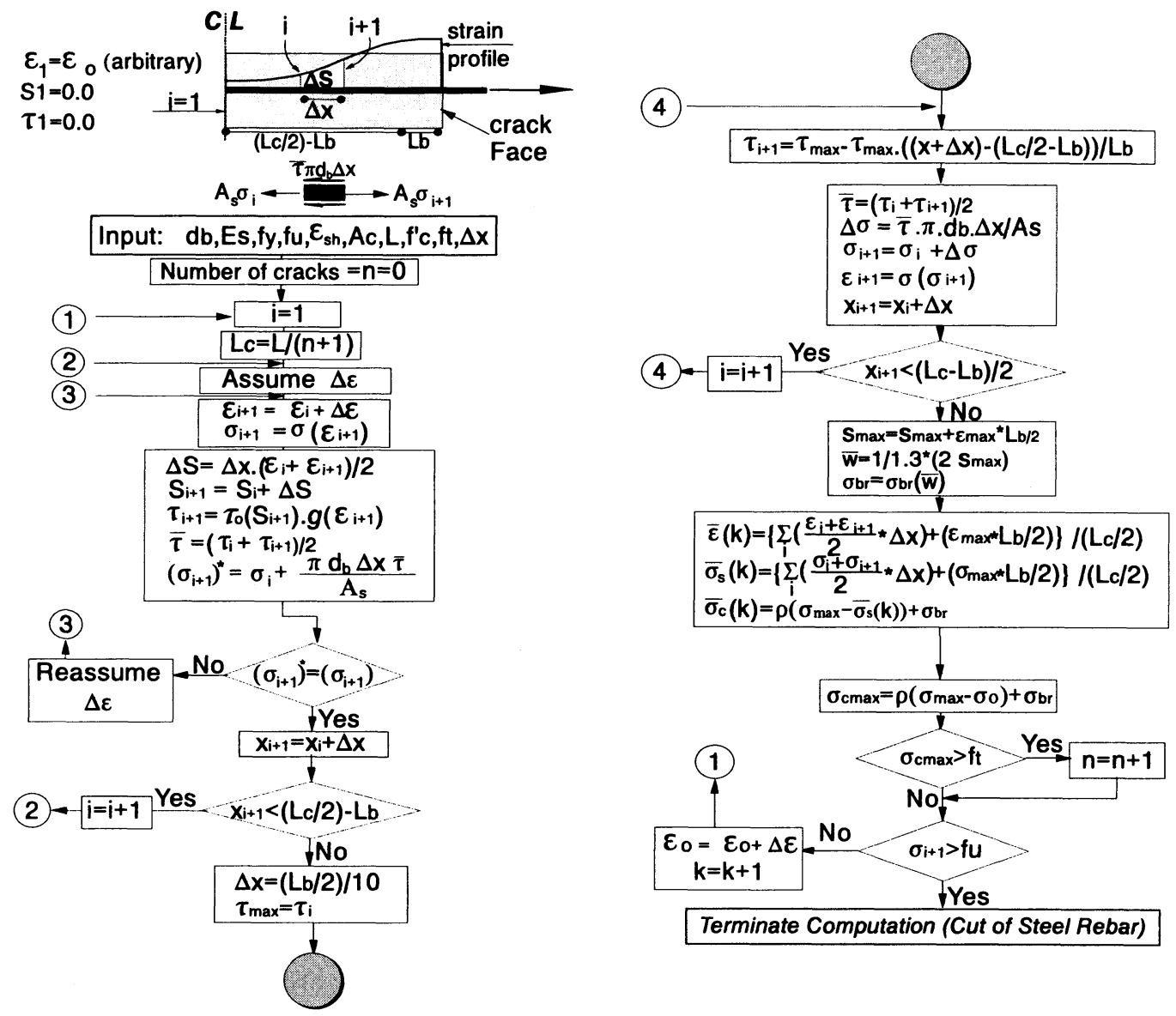

Fig. 6 Flow chart of solving bond governing equations with finite discretization

Average Stress (MPa)

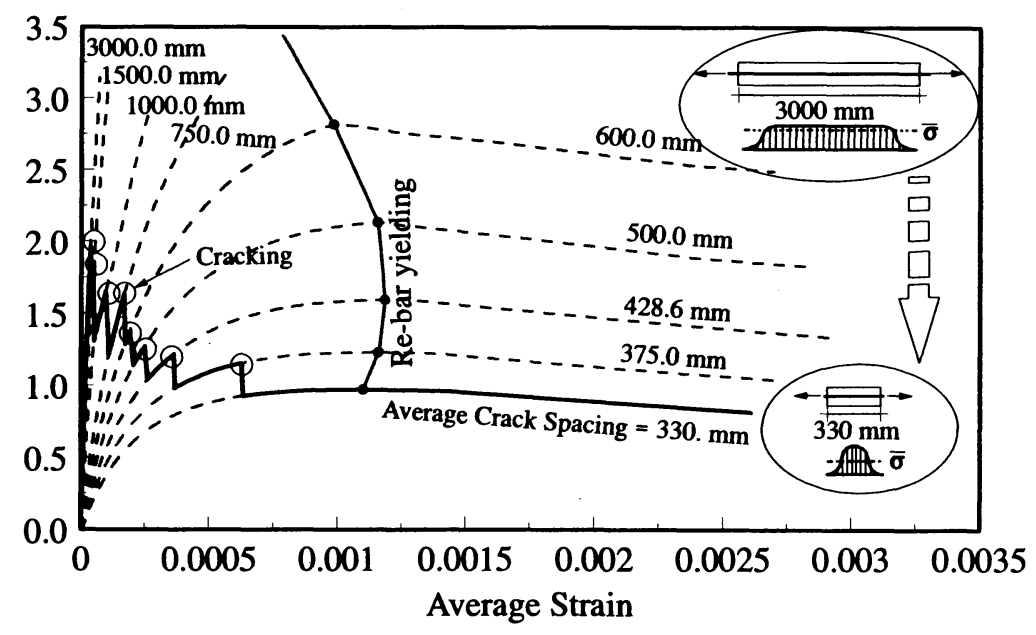

Fig. 7 Cracking of concrete 
Average Stress (MPa)

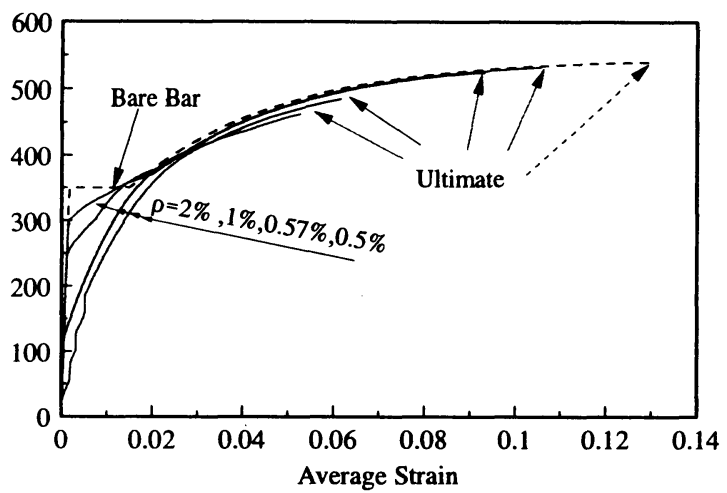

Fig. 8 Average response of reinforcement with different reinforcement ratios

Average Stress (MPa)

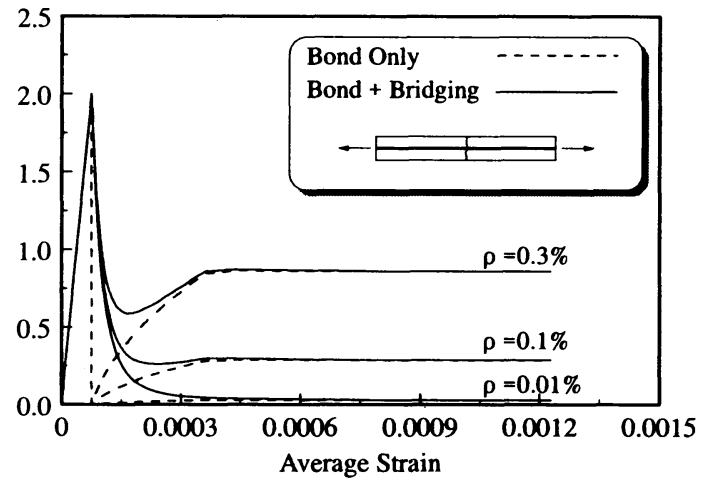

Fig. 10 Tension softening effect on tension stiffening of RC with low reinforcement ratio

Fig. 8 shows the average response of reinforcement at different reinforcement ratios compared to the bare bar behavior. In the analysis the ultimate average strain is defined as the average strain at which the local steel stress at the cracked section reaches the ultimate local stress. In this figure, it can be seen that the average yield stress decreases with the decrease of reinforcement ratio. It is also obvious that the higher the reinforcement ratio, the higher the ultimate average strain, i.e. the higher the ductility.

Fig. 9 shows the average tensile response of concrete for different reinforcement ratios in comparison with the present model by Okamura and Maekawa ${ }^{5)}$. It can be seen that the analysis agrees with the model in case of normal reinforcement ratios around 1 and $2 \%$. However, for light reinforcement close to the minimum reinforcement specified in codes, the macro model underestimates
Average Stress (MPa)

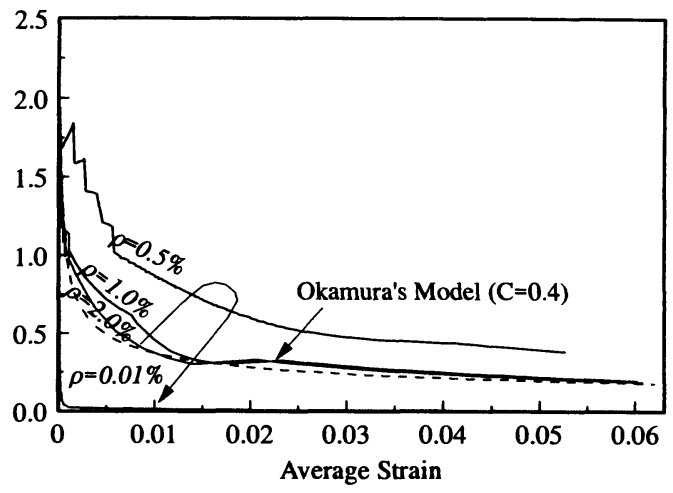

Fig. 9 Average response of concrete with different reinforcement ratios

Average Stress (MPa)

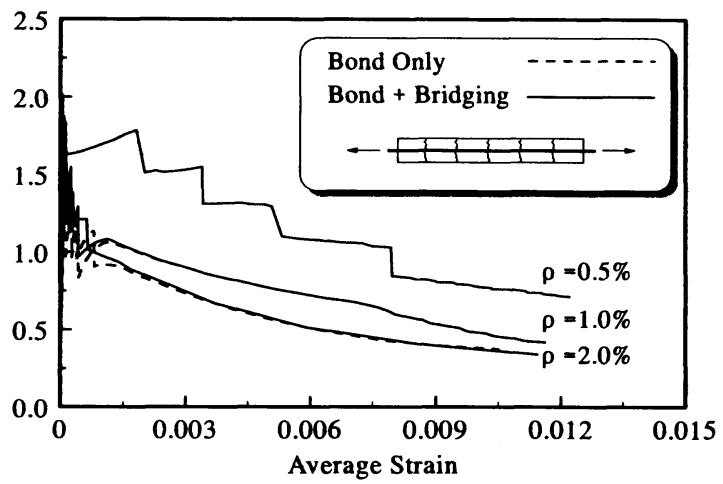

Fig. 11 Tension softening effect on tension stiffening of RC with ordinary reinforcement ratio

the tension stiffening of concrete. In case of very small reinforcement ratio or plain concrete, the model on the contrarily overestimates the tension stiffening of concrete. This means that the tension stiffening model of Okamura and Maekawa ${ }^{5)}$ is reasonably valid in case of ordinary reinforcement ratio, but it should be a versatile one depending on the reinforcement ratio and material strength.

Fig. 10 and Fig. 11 illustrate the analysis of two groups, one with low reinforcement ratio where only one crack is computed while the other with ordinary reinforcement where several cracks are predicted. For the low reinforcement ratio group, the contribution of the bridging stresses is significant. Increasing the reinforcement ratio leads to increasing the contribution of bond compared to the bridging stress even in the one crack case. The bridging stress can be omitted compared to the bond in high reinforcement group as shown in Fig. 11. 
Average Stress (MPa)

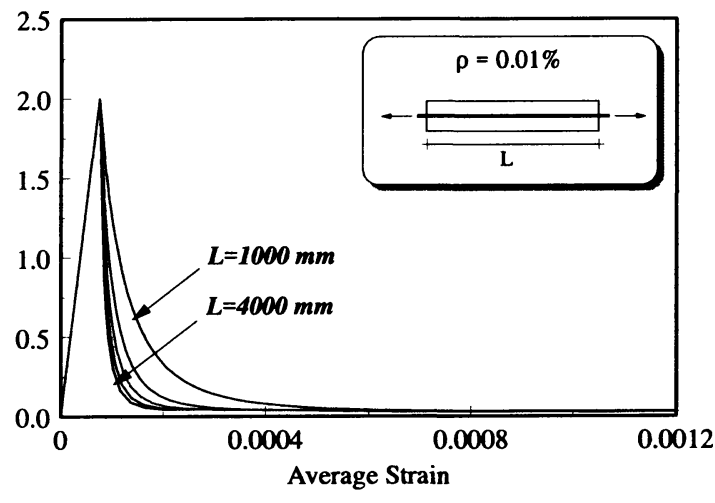

Fig. 12 Size effect on average response of concrete with very low reinforcement ratio

Average Stress (MPa)

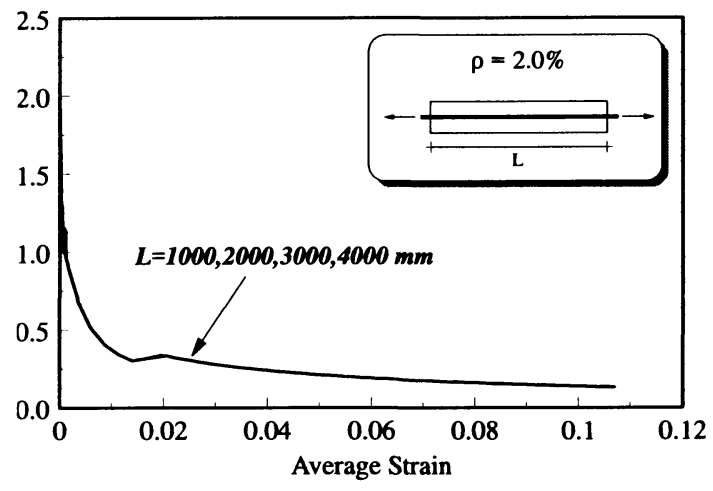

Fig. 13 Size effect on average response of concrete with ordinary reinforcement ratio

Fig. 12 and Fig. 13 shows the gauge length effect on the average response of concrete. Comparing two cases, one with heavy reinforcement and the other with light reinforcement, it can be observed that, the tension stiffening is more stable and independent on gauge length for the heavy reinforcement, while it depends very much on the gauge length in the case of low reinforcement or plain concrete. In fact, this is due to the localization of cracks in lightly reinforced concrete, causing a behavior similar to plain concrete and the average response becomes dependent on the gauge length. On the other hand, for reinforced concrete with high reinforcement ratio, the cracking is controlled by the reinforcement through bond mechanism resulting in an almost equal crack spacing no matter how different the gauge lengths are.

\section{EXPERIMENTAL VERIFICATION}

\section{(1) Comparison with the Experimental Work of Belarbi and Hsu ?}

As a verification of the analysis, a comparison with experimental work conducted by Belarbi and Hsu ${ }^{6)}$ was carried out. The experiments were carried out on full-size reinforced concrete panels $1400 \times 1400 \times 180 \mathrm{~mm}$. Specimens were first subjected to tension in the horizontal direction. After attaining a described average tensile strain in the panel, compressive stresses were gradually applied in the vertical direction until failure keeping the average tensile strain developed in the initial testing phase. A comparison with those experiments is shown in Fig. 14. On the same graphs, the analysis done by Belarbi and $\mathrm{Hsu}^{6}$ is plotted. The author's analysis seems to be better than Belarbi's analysis especially in panel E4-0.5 with a reinforcement ratio of $0.5 \%$. In fact the reinforcement ratio in this panel is low resulting in a relatively large crack spacing and a stress distribution far from that proposed by Belarbi.

\section{(2) Comparison with the Experimental Work of Shima et al. ${ }^{4)}$}

Another verification of the analysis is carried out through a comparison with experimental work conducted by Shima et al. ${ }^{4)}$ as shown in Fig. 15, 16, and 17. The tested specimens are $2700 \mathrm{~mm}$ in length. The length was selected to be long enough to correctly represent the average response since the longer specimen, which includes more cracks, will give higher accuracy. Cross sections of $150 \times 200$ $\mathrm{mm}$ and $200 \times 250 \mathrm{~mm}$ were used. A deformed steel bar having a diameter of $19 \mathrm{~mm}$ was used and reinforcement ratio was adjusted by changing the cross sectional area of concrete. The analysis agrees well with the reality.

\section{(3) Test Specimens of the Author a) Introduction}

Test specimens of Shima et al. ${ }^{4)}$ were tested up to an average strain of $1 \sim 2 \%$. They were not loaded to failure. Also, specimens with very low reinforcement ratio, where the cracking behavior is localized, were not tested.

As a completion and supplementation of Shima's experimental work, the authors tested 3 specimens of which two were loaded up to failure. The reinforcement ratio of 2 specimens were selected to be slightly larger than the critical reinforcement ratio and the third one was smaller than the critical 
Average Stress (MPa)

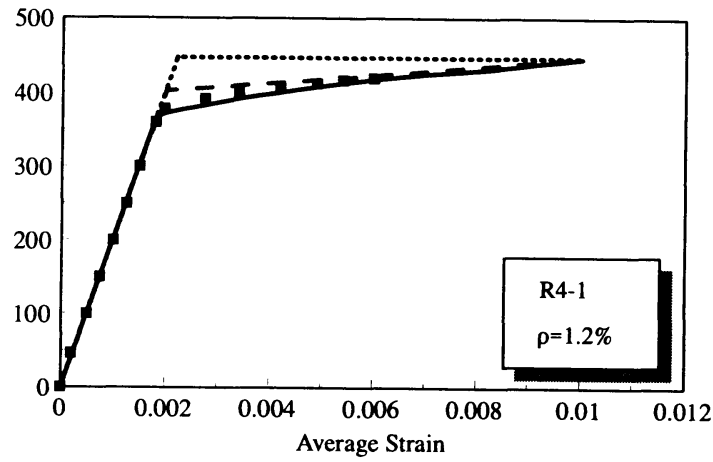

Average Stress (MPa)

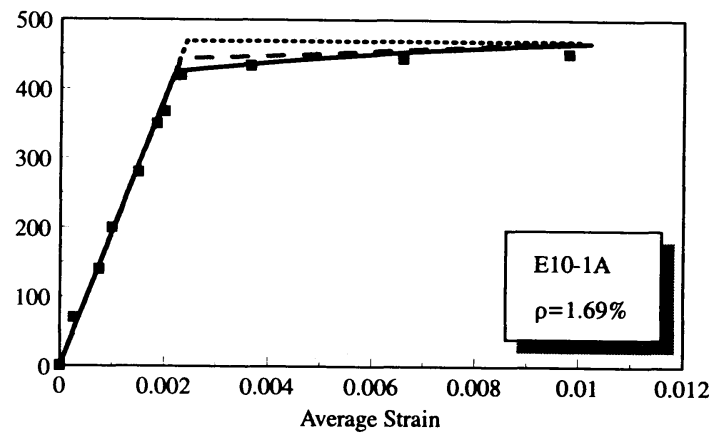

Average Stress (MPa)
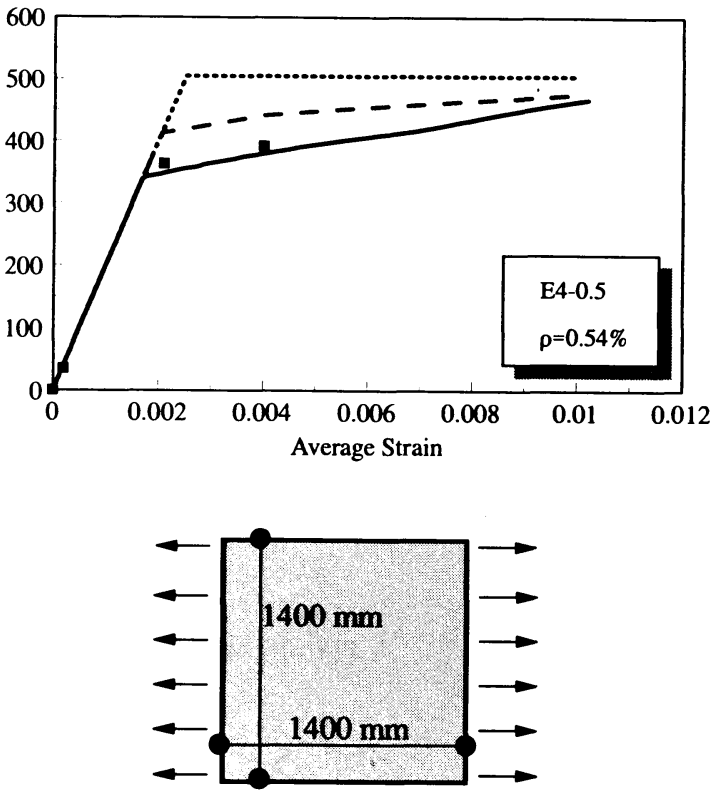

Average Stress (MPa)

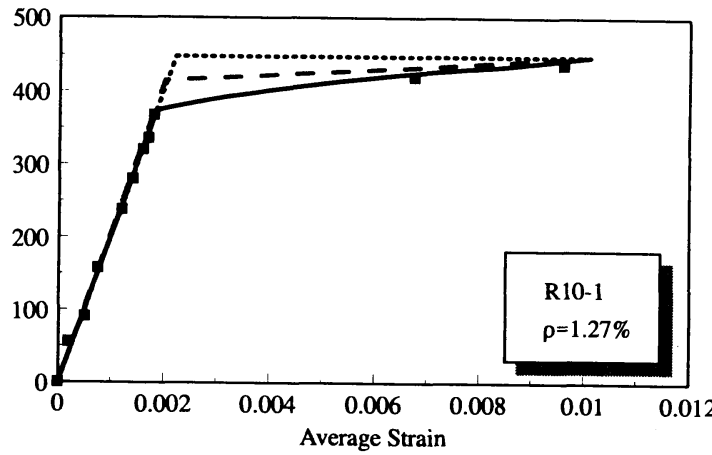

Average Stress (MPa)

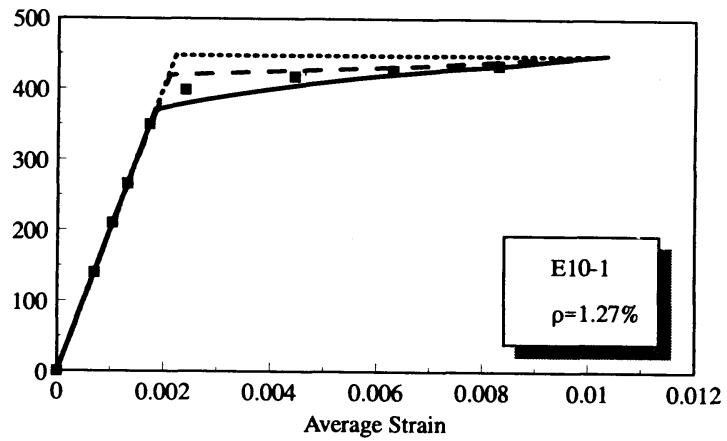

Average Stress (MPa)

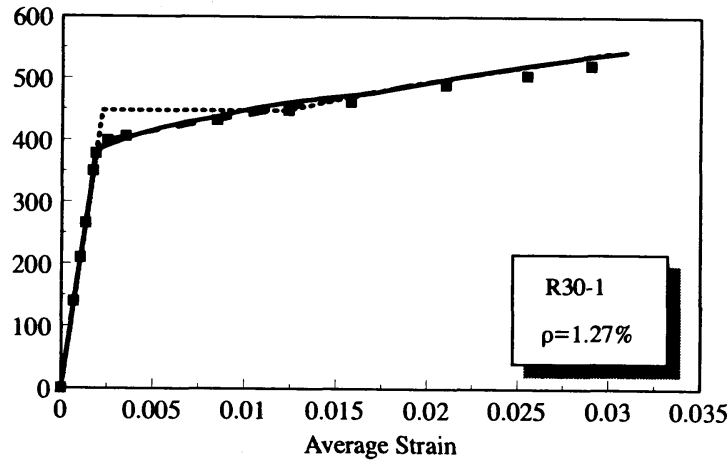

Bare Bar

Author's Analysis

Belarbi's Model

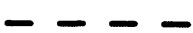

Experiment

Fig. 14 Average response of re-bars: A comparison with the experimental and theoretical work of Belarbi and Hsu ${ }^{6)}$ 
Average Stress (MPa)

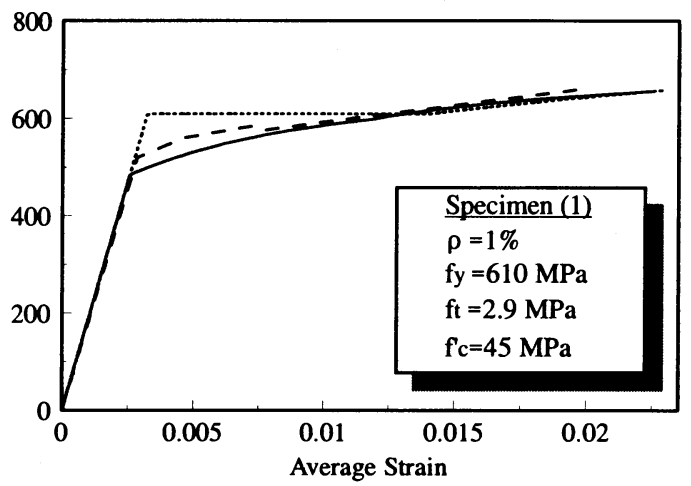

Average Stress (MPa)

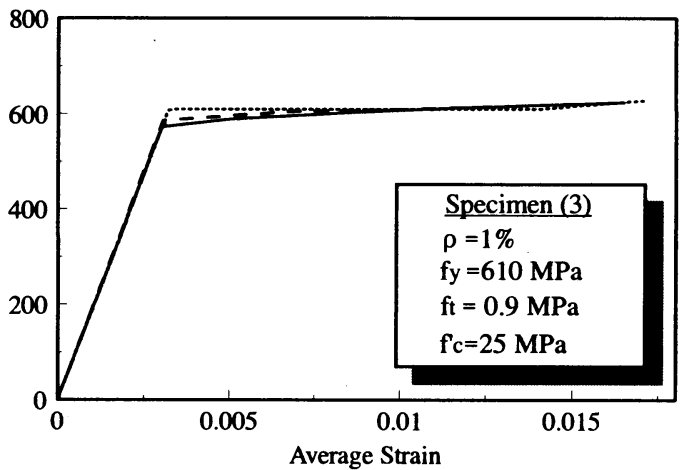

Average Stress (MPa)

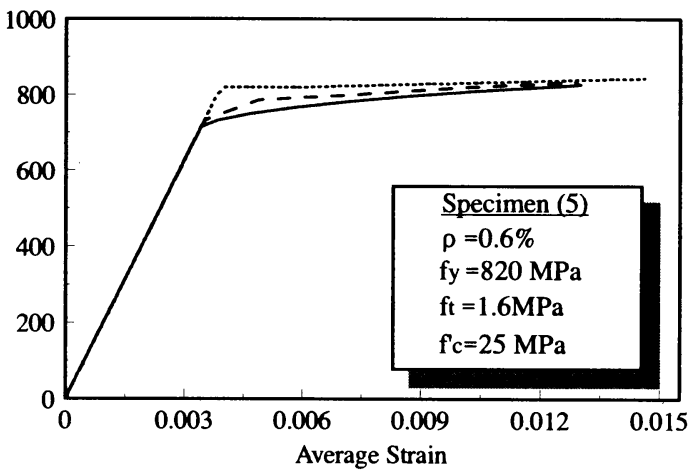

Average Stress (MPa)

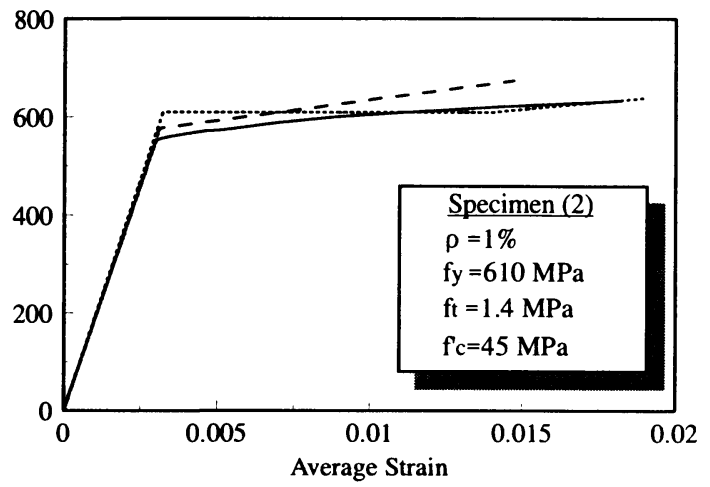

Average Stress (MPa)

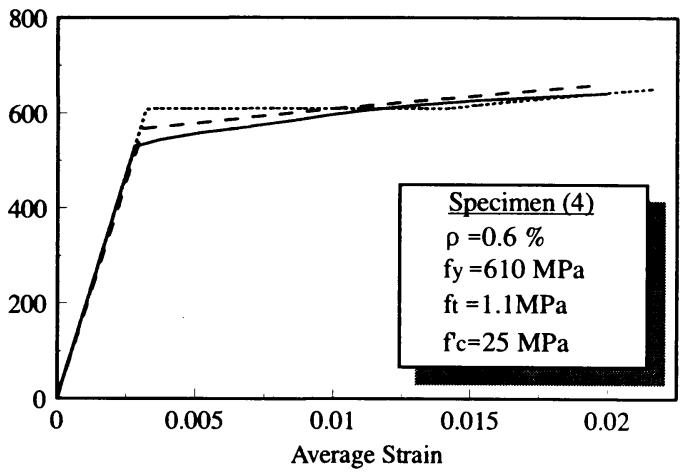

Average Stress (MPa)

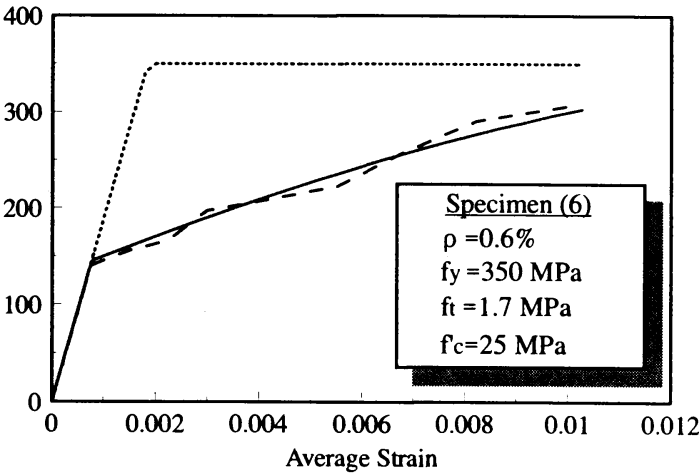

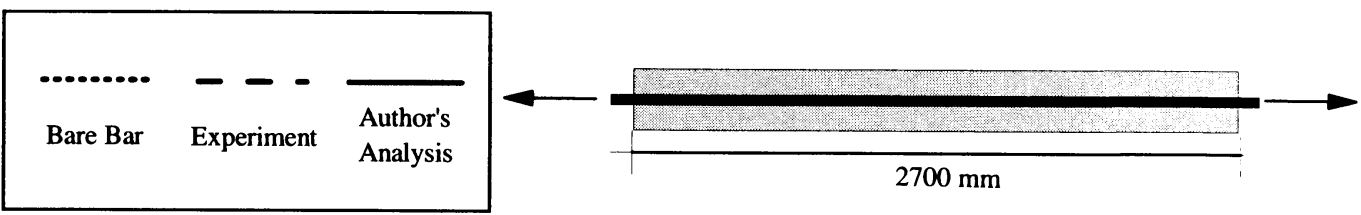

Fig. 15 Average response of reinforcement: A comparison with the experimental work of Shima et al. ${ }^{4}$ 
Average Stress (MPa)

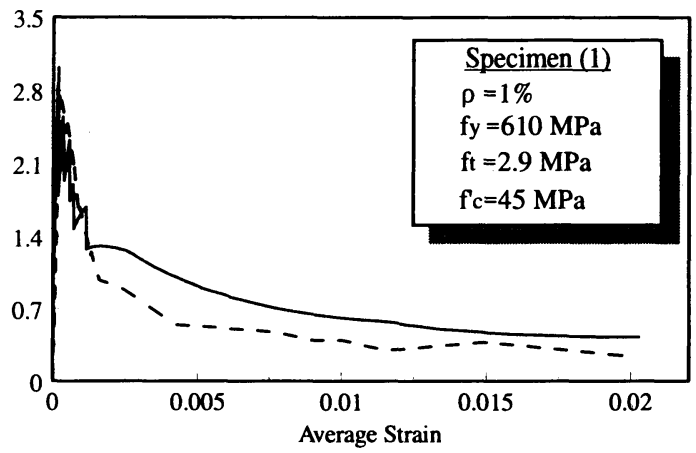

Average Stress (MPa)

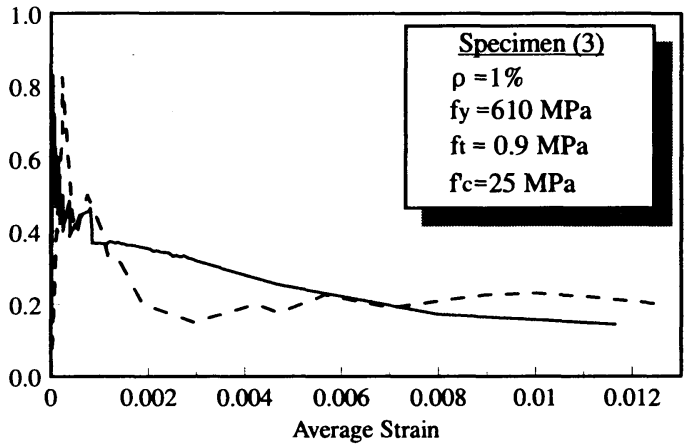

Average Stress (MPa)

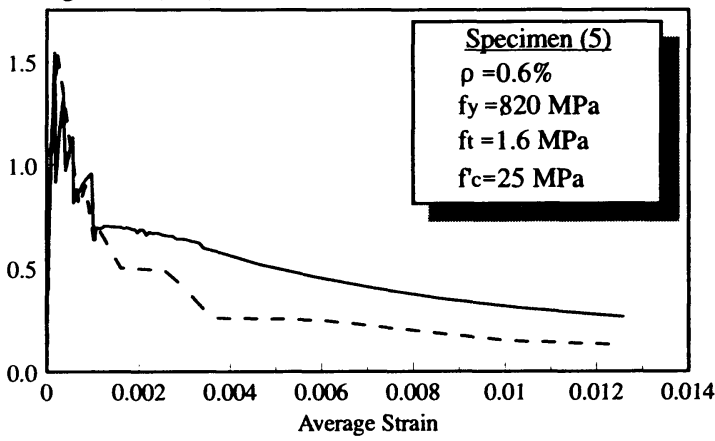

Average Stress (MPa)

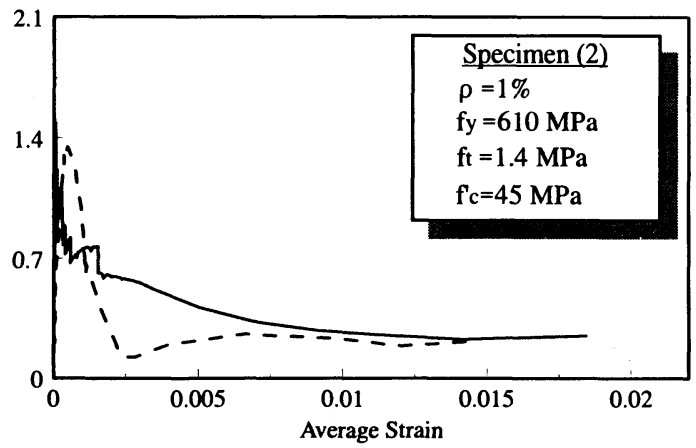

Average Stress (MPa)

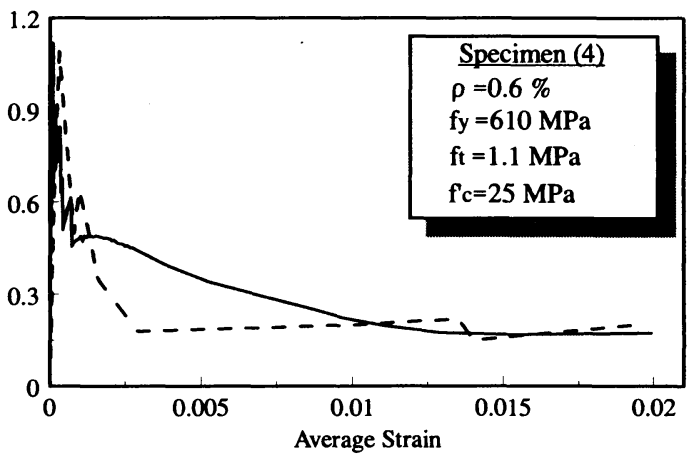

Average Stress (MPa)

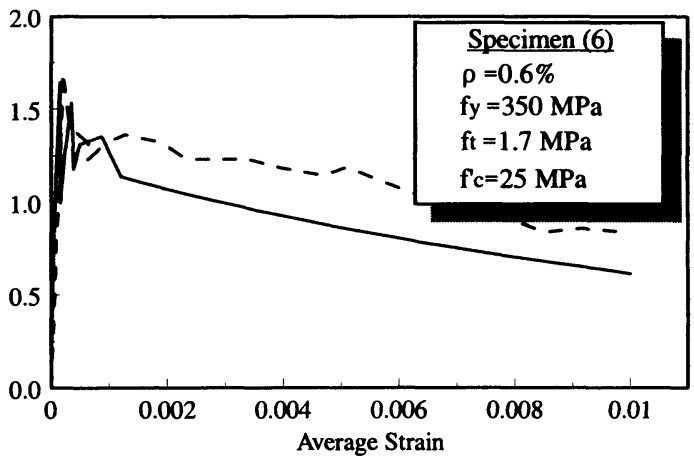

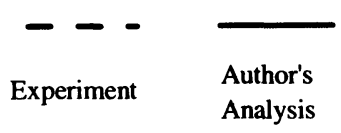

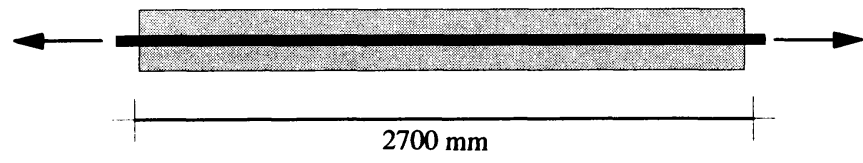

Fig. 16 Average response of concrete: A comparison with the experimental work of Shima et al. ${ }^{4)}$ 

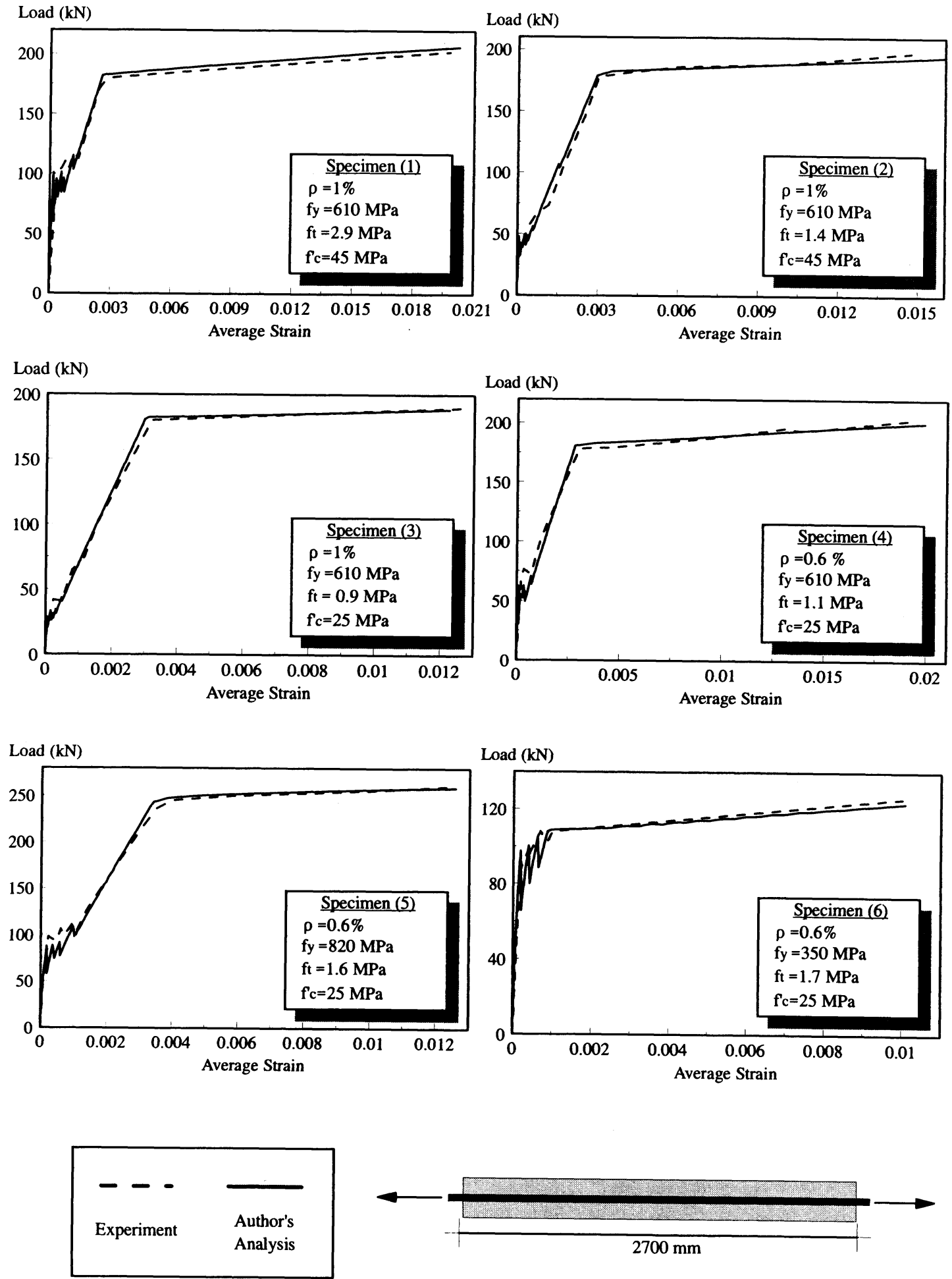

Fig. 17 Average response of RC: A comparison with the experimental work of Shima et al ${ }^{4)}$ 


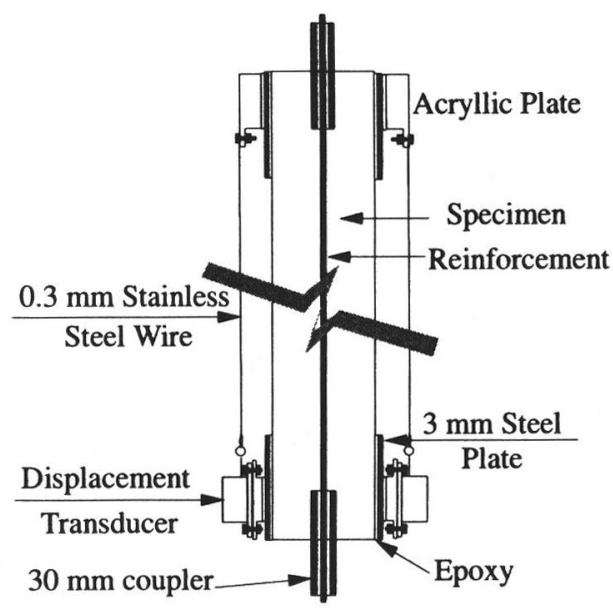

Fig. 18 Specimens' details

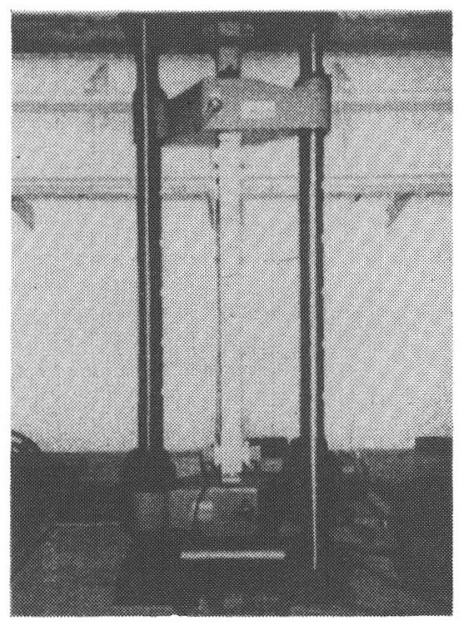

Fig. 19 Loading set-up

reinforcement ratio, which is defined as,

$$
\rho_{\text {cr }}=\frac{f_{t}}{f_{y}}
$$

When the reinforcement ratio equals to the critical reinforcement ratio, the yielding load equals to the cracking load. If the reinforcement ratio is less than the critical reinforcement ratio, the reinforced concrete behavior is expected to be similar to plain concrete behavior and cracking is expected to be localized. In other words, once the first crack occurs, the reinforcement starts to yield and no more cracks or few numbers of cracks are generated.

\section{b)Specimens}

Fig. 18 illustrates the details of the specimens and connected displacement transducers. The length of the specimens was $1700 \mathrm{~mm}$. It was selected as long as possible according to the laboratory facilities. The cross section of all specimens was $100 \times 100 \mathrm{~mm}$. A deformed reinforcing bar was used and no stirrups were used. Specimens (1) and (2) were reinforced with $10 \mathrm{~mm}$ deformed bar, whereas specimen (3) was reinforced with $6 \mathrm{~mm}$ deformed bar. The reinforcement ratio of specimens (1) and (2) were $0.75 \%$, which were slightly larger than the critical reinforcement ratio, whereas the reinforcement ratio of specimen (3) was $0.32 \%$ which was less than the critical reinforcement ratio. A $30 \mathrm{~mm}$ coupler was attached to the end of reinforcing bar, where the gripping and loading is applied, to avoid yielding of the reinforcing bars before cracking of concrete. This was essential for specimen (3) where the yielding load is smaller than the cracking load. However, the coupler was used also in specimens (1) and (2) since the reinforcement ratio is close to the critical reinforcement ratio. The testing machine used is a universal one with $1000 \mathrm{kN}$ capacity. Loading setup and testing machine are shown in Fig. 19. The total elongation of the specimen was measured using two displacement transducers on two sides of the specimen. The displacement transducers were attached to $3 \mathrm{~mm}$ steel plates which were stuck on the concrete face by epoxy material as shown in Fig. 18. The purpose of those steel plates was to prevent any possible cracks beneath it, which would affect the transducers' readings. Six electrical strain gauges were attached on both sides the reinforcing bar at its center and $150 \mathrm{~mm}$ far.

\section{c)Test Results}

The Results of those experiments are shown in Fig. 20 through Fig. 27. The analysis fairly agrees with the experiments. It can also be concluded that the crack spacing prediction is reasonable. In specimen (3), the analysis agrees with the experiment in predicting only one crack. This is due to the small reinforcement ratio used. However, the analysis computes only up to the ultimate point of stress-strain relationship of the steel bar. Thus, the descending portion of the load is not considered in the analysis. This can explain the difference in the ductility at failure between the experiment and the analysis. In specimen (2), the descending branch is not long compared to specimen (3). That is due to the fact that in specimen (2) there are several cracks, but the failure of reinforcement occurs only in one crack. Then, the total elongation is not much affected by that descending branch. 
Load (kN)

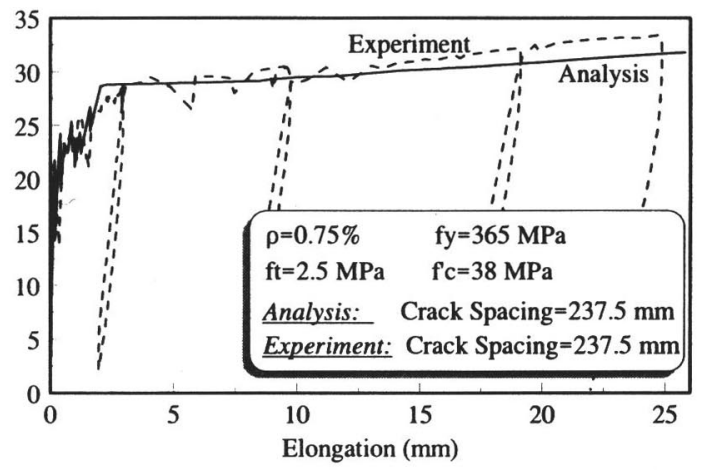

Fig. 20 Specimen(1): Experimental verification in tension

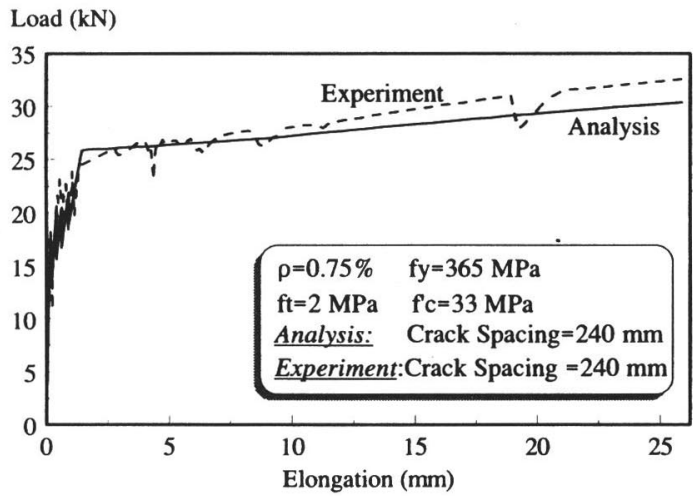

Fig. 22 Specimen(2): Experimental verification in tension

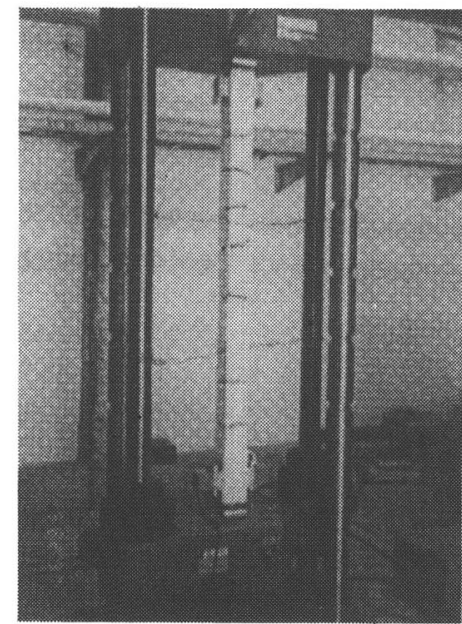

Fig. 24 Specimen(2): Observed cracking pattern

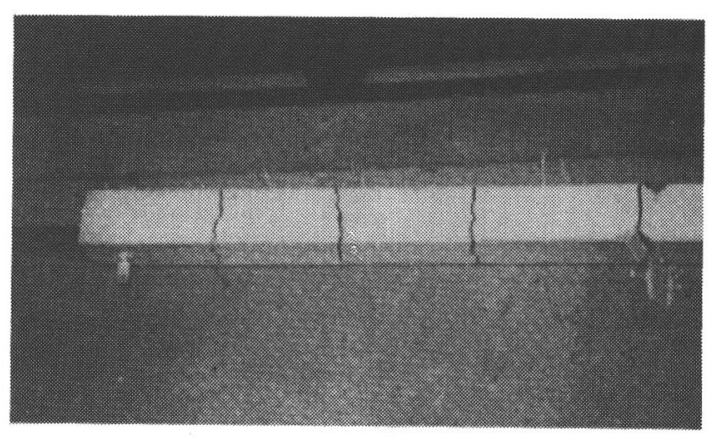

Fig. 21 Specimen(1): Observed cracking pattern

Load (kN)

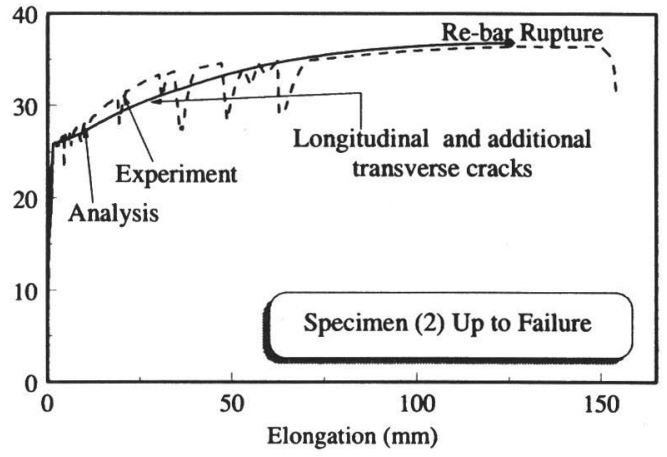

Fig. 23 Specimen(2) up to failure: Experimental verification in tension

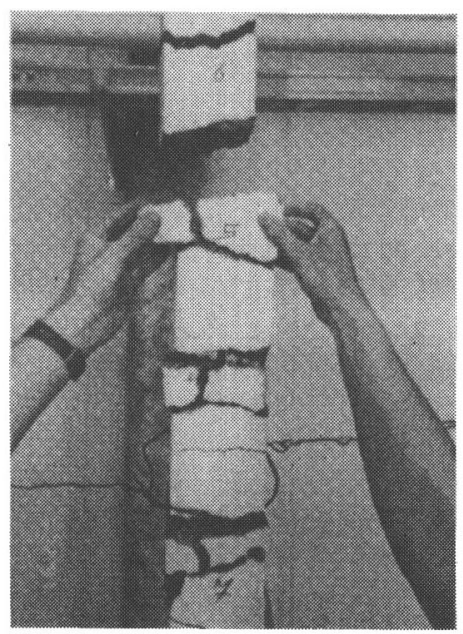

Fig. 25 Specimen(2): Observed cracking pattern at failure 


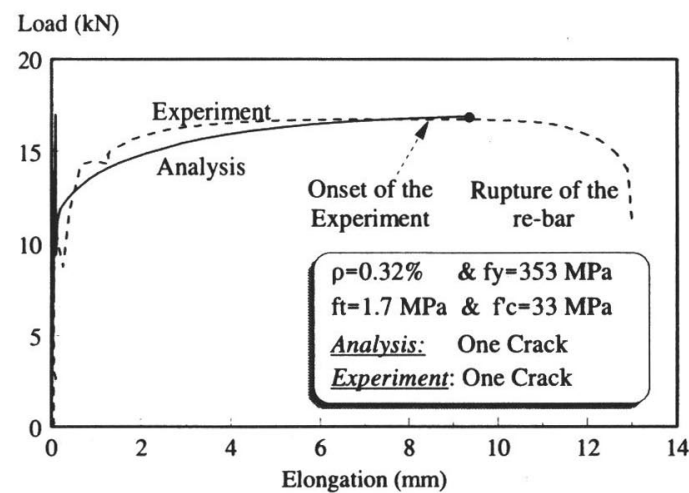

Fig. 26 Specimen(3): Experimental verification in tension

Fiber Stress (MPa)

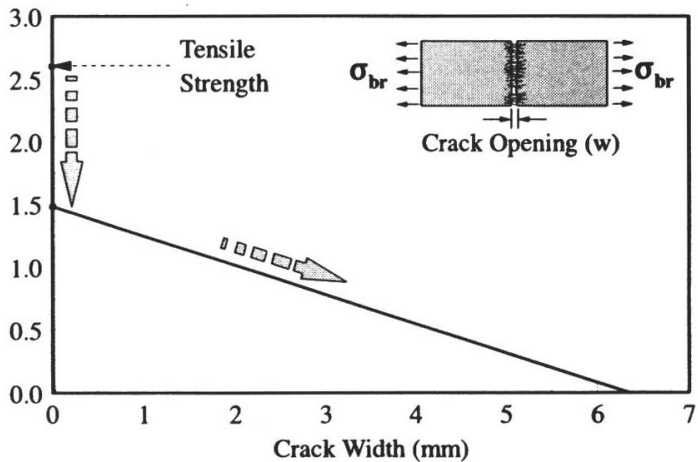

Fig. 28 Bridging stress of SFRC (Nanakorn et al. ${ }^{9)}$ )

\section{TENSION STIFFENING OF SFRC}

When crack is generated in SFRC, the steel fibers bridge the crack and transfer tensile stress between the two cracked portions of concrete. This mechanism of stress transfer allows the concrete to carry more tensile force, i.e. it increases the tension stiffening of concrete. The analysis of tension stiffening of SFRC can be carried out in a similar manner to that used in chapter 3 . If the bridging fiber stress can be got experimentally as a function of the crack width, the tension stiffening can be analyzed as shown in Fig. 28 and Fig. 29.

As an example, Fig. 29 shows the analysis of two tension members having the same reinforcement ratio. One of them is ordinary $\mathrm{RC}$, while the other is SFRC. The bridging stress of the fibers was determined experimentally as shown in Fig. 28. In spite of the fact that the tensile strength of SFRC is higher than that of normal RC, the tensile strength of both RC and SFRC was intentionally assumed to be the same in order to

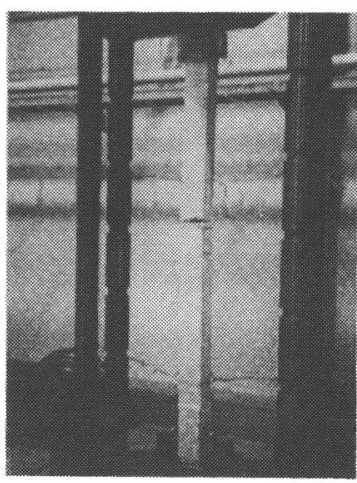

Fig. 27 Specimen(3): Observed cracking pattern at failure

Average Stress (MPa)

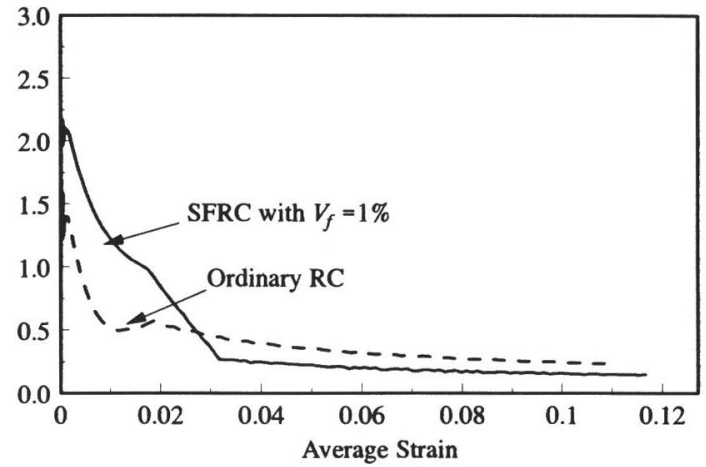

Fig. 29 Tension stiffening for SFRC

discuss the effect of fiber on tension stiffening and ductility regardless the material strength. It can be obviously seen that, at an average strain of $3 \%$ the tension stiffening of SFRC becomes smaller than that of ordinary RC. This can be explained by the fact that, in SFRC specimen the existence of fibers causes more stress to be carried by concrete, hence more cracks are developed. At an average strain of $3 \%$ bridging stress becomes zero due to cut and/or the pullout of fibers. Thus, the tension stiffening at that moment depends only on the crack spacing; the smaller the crack spacing the smaller the tension stiffening. However, since in reality the tensile strength of SFRC is higher than that of ordinary RC, the crack spacing may be larger in case of SFRC leading to higher tension stiffening even after the cut and/or pullout of fibers.

\section{CONCLUSIONS}

The conclusions of this paper can be summarized into the followings: 
1) Based on the microscopic bond-slip-strain model, bond deterioration, and tension softening at crack surface, the stress profile as well as the strain profile of reinforcing bars embedded in concrete can be computed. Hence, the macro average stressaverage strain relationship of reinforcing bars as well as the tension stiffening of concrete can be computed. From the microscopic behavior of reinforced concrete, the macroscopic behavior can be detected.

2) Using a simple stress-based method, the average crack spacing can be effectively computed.

3) In the analysis, the ultimate average strain can also be computed.

4) In reinforced concrete members with ordinary reinforcement ratio, the tension softening at the crack surface can be neglected without considerable influence on the average response of concrete and reinforcement. However, in very lightly reinforced concrete or plain concrete, tension softening at fractured crack planes is predominant and has to be taken into consideration

5) The analysis can also compute the average response of SFRC taking into consideration the bridging stress transferred through the steel fibers.

\section{REFERENCES}

1) Goto, Y.: Cracks formed in concrete around deformed tension bars, ACI Journal, Proceedings Vol. 68, No. 4, pp. 244-251, 1971.

2) Floegl, H. and Mang, H.: Tension stiffening concept based on bond slip, J. of Structural Div., ASCE, Vol. 108, No.
ST12, 1982

3) Rizkalla, S. and Hwang, L.: Crack prediction for members in uniaxial tension, ACI Journal, Proceedings Vol.81, No.44, pp. 572-579, 1984.

4) Shima H., Chou L. and Okamura, H.: Micro and macro models for bond in reinforced concrete, Journal of The Faculty of Engineering, The University of Tokyo (B), Vol.XXXIX, No 2, pp. 133-194, 1987.

5) Okamura, H. and Maekawa, K.: Nonlinear Analysis And Constitutive Models of Reinforced Concrete, Gihodo, Tokyo, 1991.

6) Belarbi, A. and Hsu, T.: Constitutive Laws Of Reinforced Concrete in Biaxial Tension-Compression, Research Report UHCEE 91-2, University of Houston, Department of Civil and Environmental Engineering, 1991.

7) Uchida, Y., Rokugo, K. and Koyanagi, W.: Determination of tension softening diagrams of concrete by means of bending tests, Proceedings of JSCE, Vol. 14, No. 426, pp. 203-212, 1991.

8) Qureshi, J. and Maekawa, K.: Computational model for steel bar embedded in concrete under combined axial pullout and transverse shear displacement, Proc. of JCI, Vol.15, No. 2, pp 1249-1254, 1993.

9) Nanakorn, P., Horii, H. and Matsuoka, S.: A fracture mechanics-based design method for SFRC tunnel linings, $J$. of Materials, Conc. Struct., Pavements, Vol.30, No.532, pp. 221-233, 1996.

10) Salem, $H$. and Maekawa, $K$.: Tension stiffness for cracked reinforced concrete derived from micro-bond characteristics, Proc. of JCI, Vol.19, No.2, pp. 549-554, 1997.

11) Salem, H. and Maekawa, K.: Computational model for tension stiffness of cracked reinforced concrete derived from micro-bond characteristics, Proc. Of the Sixth East Asia-Pacific Conference on Structural Engineering \& Construction, Taipei, Vol.3,pp. 1929-1934, 1998.

(Received March 23, 1998)

\section{ひび割れを有するコンクリート及び鉄筋の}

\section{高塑性域における空間的な平均引張機構}

$$
\text { サレムハメッド・前川宏一 }
$$

本研究の目的は, コンクリートと鉄筋の間の局所的な付着機構に基づき， R C 部材における鉄筋とひび 割れを有するコンクリートの, 空間的な平均応力一平均ひずみ関係を得る事にある. 提案する数值解析手法 によって、破断が起こるときのひび割れ間隔と、鉄筋の終局平均ひずみを予測可能であることを示した。さ らに, 系統だった検証実験により, 提案したモデルの有効性を明らかにした. 